MATEC Web of Conferences 33, 03021 (2015)

DOI: $10.1051 /$ matecconf/ 20153303021

(C) Owned by the authors, published by EDP Sciences, 2015

\title{
Investigation of TiNi shape memory alloy for thermosensitive wire drive
}

\author{
Eugene Ostropiko ${ }^{1, a}$, Alexander Razov ${ }^{1}$ and Alexander Cherniavsky ${ }^{2}$ \\ ${ }^{1}$ Saint-Petersburg State University, Universitetskii pr. 28, Saint-Petersburg, 198504 Russia \\ ${ }^{2}$ S.P. Korolev Rocket and Space Corporation ENERGIA, 4A Lenin Street, Korolev, Moscow area, 141070, Russia
}

\begin{abstract}
TiNi shape memory alloys are nowadays widely used in engineering and medicine. The unique capabilities of this material are particularly apparent in applications for space technology. One of the actual present problems is the design of thermosensitive devices for space applications. In this work, we investigated a TiNi alloy as a working element material for the thermosensitive wire drive as an actuator. An optimum thermomechanical treatment of NiTi alloys was selected based on the analysis of functional and mechanical properties. It consists of a multi-cycle implementation of transformation plasticity under $220 \mathrm{MPa}$ constant stress and a shape memory effect in the free state.
\end{abstract}

\section{Introduction}

Nowadays TiNi-based shape memory alloys are expanding their applications in engineering and medicine [1-5]. Unique features of this material are especially evident in devices for space technology $[2,6,7]$. In the last decade, this field took second place in the world market of shape memory alloys after medical applications. One of the important problems, which arises today, is the design of thermosensitive devices for space applications. This work is devoted to the calculation, design and training of a TiNi shape memory alloy wire drive, providing in a temperature range from 90 to $110^{\circ} \mathrm{C}$ the necessary value of the power stroke only under the influence of heat flow from the environment.

\section{Design}

Let us assume that the TiNi shape memory alloy wire drive has to do work for moving the output element in the temperature range from 90 to $110^{\circ} \mathrm{C}$ for $5 \%$ of the original length at a constant counteracting force in the absence of gravity. The minimal initial length of the wire drive operating in the stretching mode can be found supposing that the alloy restores the above-mentioned 5\% of strain. This restoration should provide a working stroke, thermal expansion and deformation caused by an external counteracting force. Thus, it is possible to formulate an equation: $0,05 \mathrm{~L}_{0}=\mathrm{L}_{1}+10^{-3} \mathrm{~L}_{0}+\mathrm{L}_{0} \varepsilon$, where $\mathrm{L}_{0}$ is the initial length of the actuator, $\mathrm{L}_{1}$ is the actuator's stroke, $10^{-3} \mathrm{~L}_{0}$ is thermal expansion and $\varepsilon$ is the strain of the wire, or $0,05 \mathrm{~L}_{0}=\mathrm{L}_{1}+10^{-3} \mathrm{~L}_{0}+\mathrm{L}_{0} \mathrm{~F}_{\mathrm{n}} / \mathrm{SE}_{\mathrm{A}}$, where $\mathrm{F}_{\mathrm{n}}$ is an external counteracting force, $\mathrm{S}$ is the cross-sectional area of the wire and $\mathrm{E}_{\mathrm{A}}$ is the elastic modulus of the material in the austenitic state. After simple transformations, $\mathrm{L}_{0}=\mathrm{L}_{1} /\left(0,05-10^{-3}-\mathrm{F}_{\mathrm{n}} /\left(\mathrm{SE}_{\mathrm{A}}\right)\right)$.

We can obtain the value of the initial length of actuator $\mathrm{L}_{0}$ by substituting the values of the stroke, the cross-sectional area and the elastic modulus of the austenitic phase. This is the minimum possible initial length of the wire drive before preliminary straining (training). Now, we need to find a material that meets these mechanical and thermal conditions.

\section{Experimental procedure}

Taking into account the predictable shift of temperatures under tension and under the influence of preliminary deformation, the TiNi alloy with characteristic temperatures of martensitic transformations, $\mathrm{M}_{\mathrm{f}}=49^{\circ} \mathrm{C}$, $\mathrm{M}_{\mathrm{s}}=68^{\circ} \mathrm{C}, \mathrm{A}_{\mathrm{s}}=83^{\circ} \mathrm{C}$ and $\mathrm{A}_{\mathrm{f}}=104^{\circ} \mathrm{C}$, was chosen. $\mathrm{A}$ wire with a diameter of $1.1 \mathrm{~mm}$ annealed at $650^{\circ} \mathrm{C}$ for 30 minutes and quenched in water was purchased from Matek-SMA Ltd. A number of the samples underwent additional heat treatment - annealing at $500^{\circ} \mathrm{C}$ for one hour and cooling with a furnace. The characteristic temperatures after this treatment were practically unchanged: $\mathrm{M}_{\mathrm{f}}=52^{\circ} \mathrm{C}, \mathrm{M}_{\mathrm{s}}=71^{\circ} \mathrm{C}, \mathrm{A}_{\mathrm{s}}=84^{\circ} \mathrm{C}$ and $\mathrm{A}_{\mathrm{f}}=$ $103^{\circ} \mathrm{C}$. However, as it turned out, the functional properties changed significantly. Looking ahead, one can say that it was decided to use a double heat treatment. The graphs in figure 1 show heat dissipation and heat absorption upon cooling and heating obtained by using differential scanning calorimetry methods for both cases.

As a first method for preparing the wire actuator, conventional active deformation of the TiNi alloy in the martensitic state at room temperature was used. Stressstrain curves during active deformation in the martensitic state up to $15 \%$ of residual strain and the shape memory

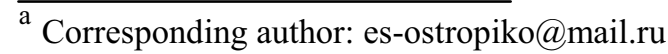


effect after the deformation process are presented in figure 2 and figure 3 respectively.

a)

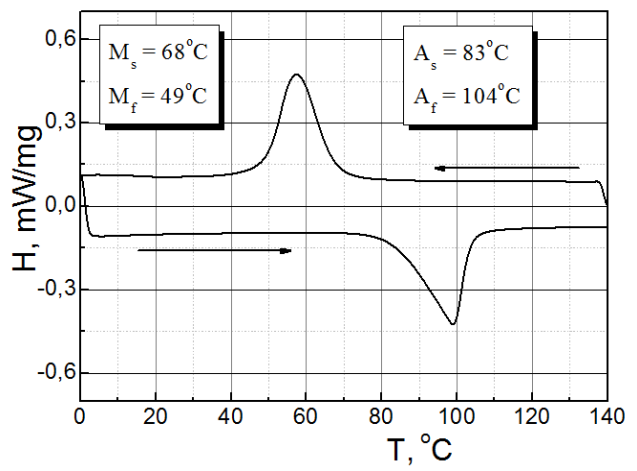

b)

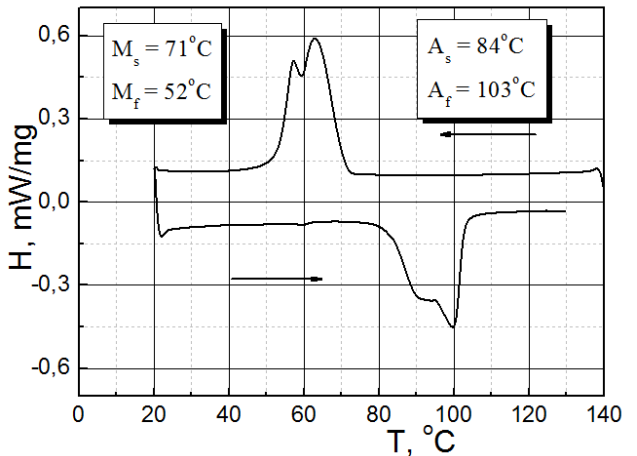

Figure 1. Calorimetric curves obtained on cooling and heating of TiNi alloy: (a) annealing at $650^{\circ} \mathrm{C}$ for 30 minutes, quenching in water, (b) additional annealing at $500^{\circ} \mathrm{C}$ for one hour, cooling with a furnace.

a)

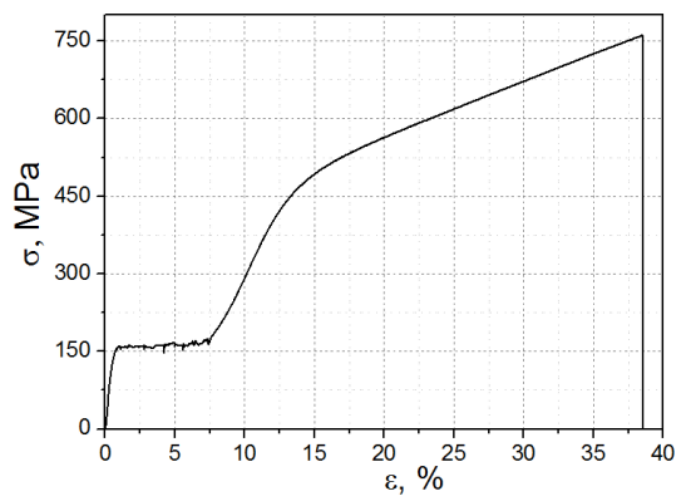

b)

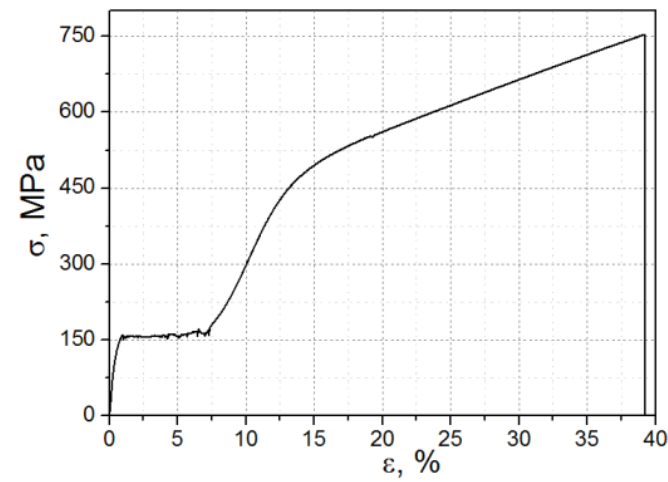

Figure 2. The stress-strain curve of the TiNi alloy: (a) after single heat treatment, (b) after double heat treatment. a)

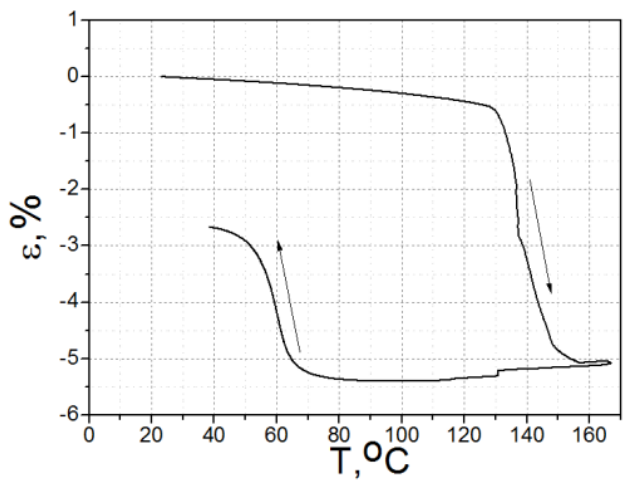

b)

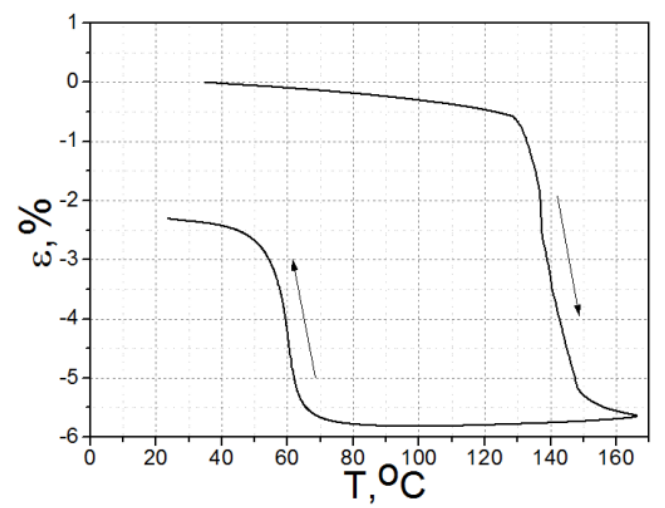

Figure 3. The shape memory effect of the TiNi alloy during heating after the active straining of up to $15 \%$ of the residual strain in the martensitic state: (a) after single heat treatment,

(b) after double heat treatment.

There is a significant shift of the characteristic temperatures of the reverse martensitic transformation after active straining in the martensitic state due to the well-known effect of martensite stabilisation [8-13]. This fact does not allow us to use this method for preparing the wire drive with the desired operation temperature range. Additionally, one can see that, after the double heat treatment, the material recovers bigger strain.

The second method for preparing the wire drive is the method using the transformation plasticity effect during cooling through the interval of the direct martensitic transformation under stress for the accumulation of the necessary strain.

The transformation plasticity effect can be observed in the following case. The sample undergoes direct martensitic transformation, passing upon cooling through the temperature range under tensile load. This process entails an intensive accumulation of strain. The accumulated strain is maintained after removing the load. On subsequent heating, a large part of this strain can be recovered due to the shape memory effect.

All functional properties of a TiNi alloy depend on the number of thermal-deformation cycles [14-21]. To determine this dependence for the given alloy, thermocycling of the wire samples under different stresses was conducted.

Cooling through the interval of the direct martensitic transformation was performed under appropriate loads, and heating through the interval of the reverse martensitic 
transformation was carried out under a stress of $10 \mathrm{MPa}$ (load is caused by design features). Scheme is shown in figure 4(a). Heating was provided by an electric current. The cycle was repeated several times. A comparison of the material behaviour after single and double heat treatments in five cycles under the stresses of 200 and $250 \mathrm{MPa}$ are shown in figure 4.

a)

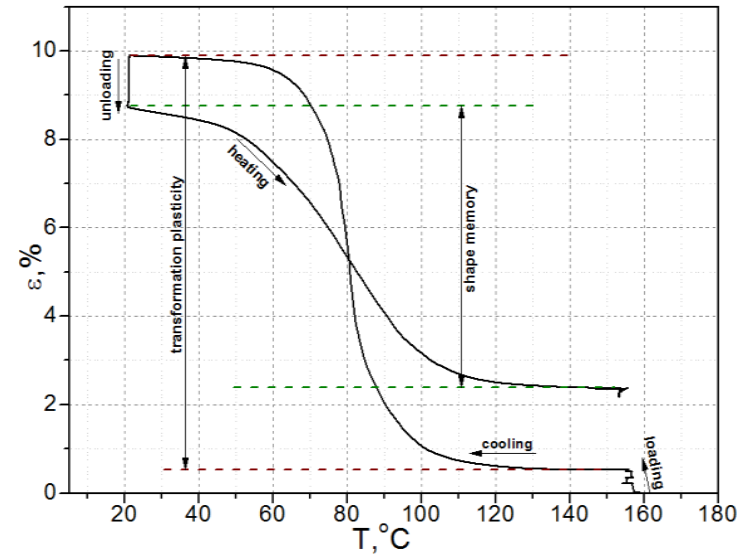

b)

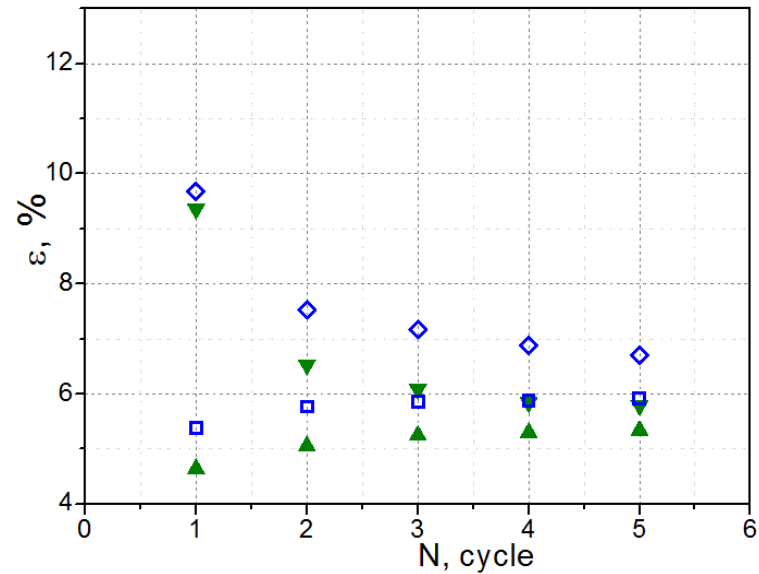

c)

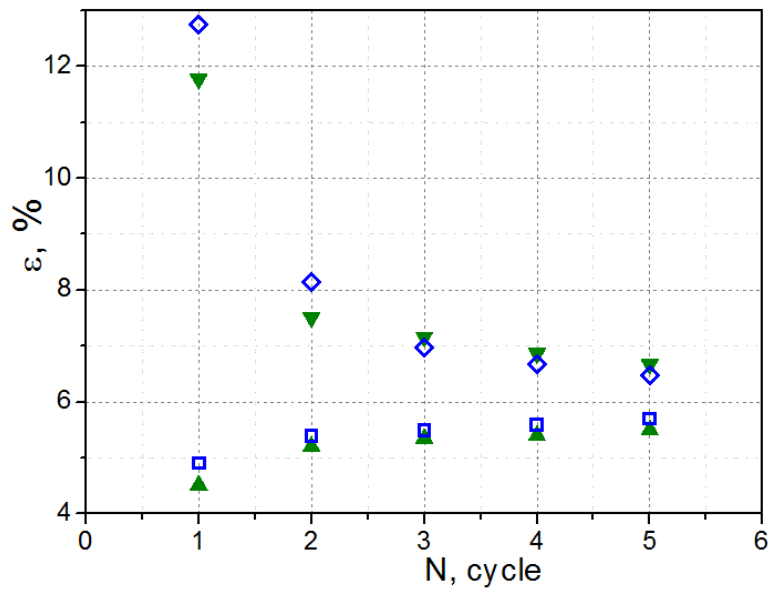

Figure 4. Diagram of a single thermal-deformation cycle (a) and dependencies of transformation plasticity under $200 \mathrm{MPa}$ (b), $250 \mathrm{MPa}$ (c) and the shape memory effects in the free state on the number of cycles.

$\nabla$ - strain accumulated as a result of transformation plasticity (single heat treatment), $\boldsymbol{\Delta}$ - shape memory effect (single heat treatment), $\diamond$-strain accumulated as a result of transformation plasticity (double heat treatment), $\square-$ shape memory effect (double heat treatment).
Obviously, the material, which underwent double heat treatment, showed a more significant shape memory effect in contrast to the material, which underwent a single supplier heat treatment. So, it was decided to use the double heat treatment for preparing the thermosensitive wire drive.

To find the optimal cycle parameters, the influence of stresses applied on the cooling through the interval of the direct martensitic transformation stage on the functional properties of the material (the effects of transformation plasticity and shape memory) was investigated (figure 5).

Relations shown in figure 5 allow us to conclude that the load approximately to $220 \mathrm{MPa}$ gives us the optimal value of the shape memory effect and the optimal ratio of the shape memory effect to the transformation plasticity effect. Though at $240 \mathrm{MPa}$ the shape memory effect was larger, there was a large accumulation of irreversible plastic strain. For this optimal $220 \mathrm{MPa}$ stress, 11 cycles were conducted that lead the values of the transformation plasticity effect and the shape memory effect to a stable state (figure 6).

a)

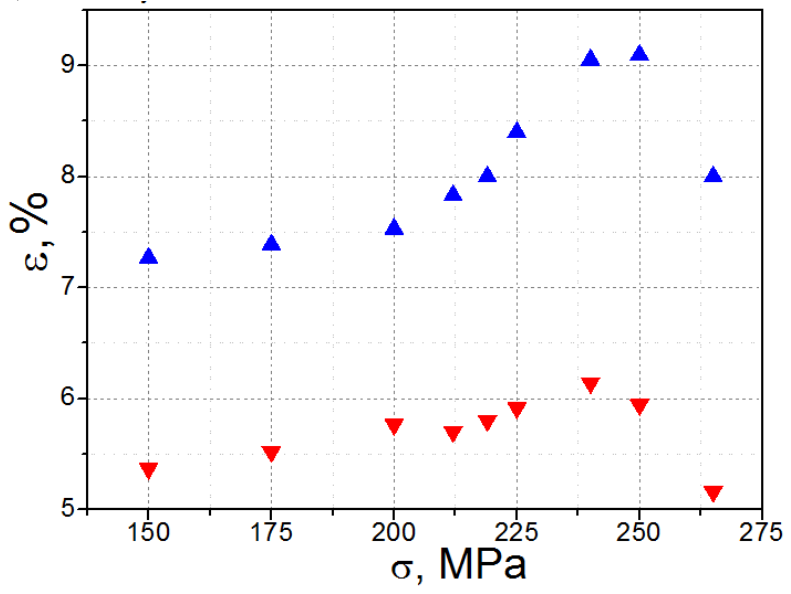

b)

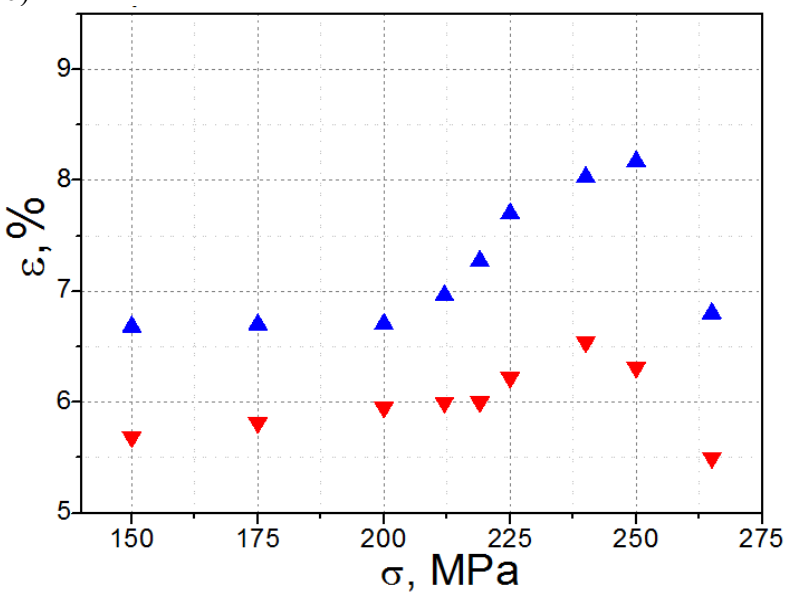

Figure 5. The dependences of transformation plasticity and the shape memory effects in the TiNi alloy on the load after double heat treatment in the second (a) and fifth (b) cycle. $\boldsymbol{\Delta}$ - transformation plasticity, $\boldsymbol{\nabla}$ - shape memory effect. 


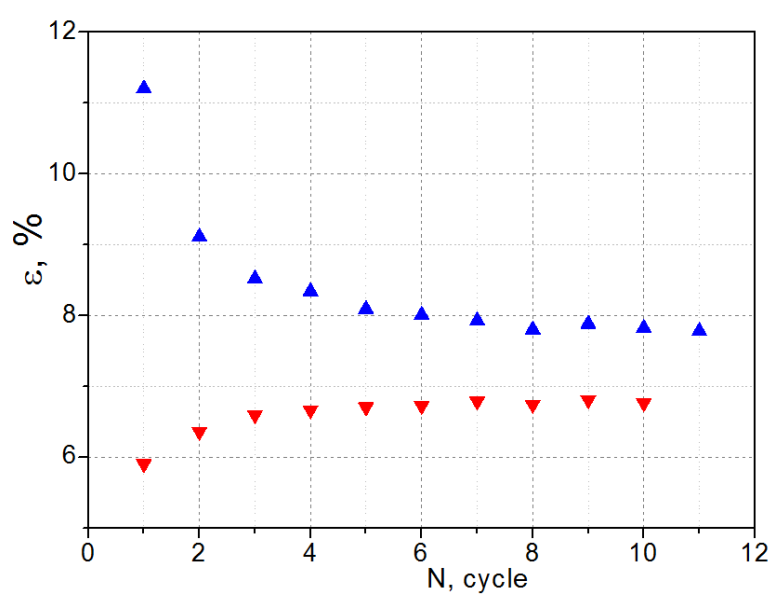

Figure 6. The dependence of transformation plasticity and shape memory on the number of cycles in the TiNi alloy after annealing at $500^{\circ} \mathrm{C}$. $\boldsymbol{\Delta}$ - transformation plasticity under 220 $\mathrm{MPa}, \boldsymbol{\nabla}$ - shape memory effect in the free state.

For a more accurate measurement, the sample carved from the wire drive after 11 cycles was heated and cooled through the range of martensitic transformations in a special dilatometric installation (figure 7).

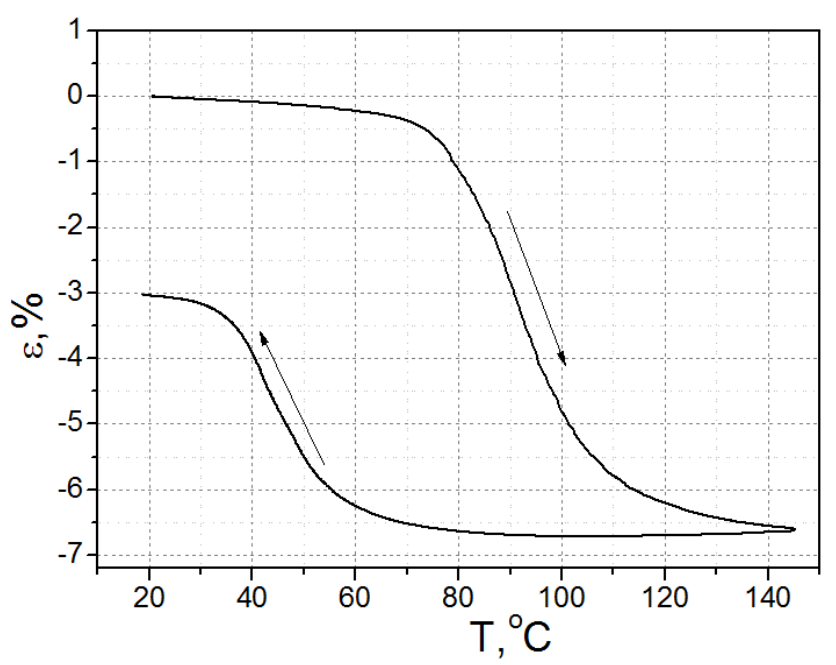

Figure 7. One-way shape memory (at heating) and two-way shape memory (at cooling) in the prepared sample after 11 training cycles.

Figure 7 shows, that restoring 5\% strain occurs at a temperature of about $100{ }^{\circ} \mathrm{C}$. So, the problem is solved and the wire drive performs the necessary stroke $(5 \%$ strain) in the desired temperature interval, $90-110^{\circ} \mathrm{C}$.

\section{Conclusion}

An example of the calculation, design and training of a TiNi shape memory alloy wire drive was demonstrated. For the manufacturing of this wire drive, various methods of heat treatment and strain accumulation have been investigated.

It was found that active straining of the TiNi alloy in a low-temperature state leads to a strong increase in strain recovery temperatures, and this is not suitable for the task.
An effective solution for the manufacture of the TiNi shape memory alloy wire drive is the use of transformation plasticity.

It was experimentally established that the strains caused by transformation plasticity and shape memory during thermal cycling asymptotically approach a constant value and vary slightly in the 9-11 cycles.

The drive thermomechanical training that satisfies the necessary values of the working element power stroke is 10 cycles of cooling under about $220 \mathrm{MPa}$ and heating in a free state.

\section{Acknowledgements}

The authors are grateful to Saint-Petersburg State University (grant \#6.37.147.2014) for supporting this research.

\section{References}

1. J.M. Jani, M. Leary, A. Subic, M.A. Gibson Mater.\& Design 56, 1078 (2014)

2. A.I. Razov, Phys. Met. Metall. 97, S97 (2004)

3. I. Khmelevskaya, E. Ryklina, A. Korotitskiy, Shape Memory Alloys: Properties, Technologies, Opportunities (Eds. Natalia Resnina, Vasili Rubanik) Trans Tech Publications Ltd, Pfaffikon, Switzerland, 603 (2015)

4. L. Petrini, F. Migliavacca, J. of Metallurgy 2011, Article ID 501483 (2011)

5. M.G. Castellano, M. Indirli, A. Martelli, Proc. of SPIE 4330, 25 (2001)

6. A. Razov, A. Cherniavsky, J. Phys. IV 112, 1173 (2003)

7. D.J. Hartl, D.C. Lagoudas, J. of Aerospace Eng. 221, 535 (2007)

8. Y. Liu, Mat. Sci. Eng. A 273-275, 668 (1999)

9. X. Ren, K. Otsuka, Mat. Sci. Forum 327, 413 (2000)

10. R. Santamarta, J. Pons, E. Cesari, C. Segui, J. Phys. IV 112, 647 (2003)

11. Y. Liu, G. Tan, S. Miyazaki, Mat. Sci. Eng. A 438440, 612 (2006)

12. X. Yan, J. Van Humbeeck, Mat. Sci. Eng. A. 558, 737 (2012)

13. P.M. Kadletz, P. Krooß, Y.I. Chumlyakov, M.J. Gutmann, W.W. Schmahl, H.J. Maier, T. Niendorf, Materials Letters 159, 16 (2015)

14. J. Van Humbeeck, J. Phys. IV 11, C4189 (1991)

15. G. Eggeler, E. Hornbogen, A. Yawny, A. Heckmann, M. Wagner, Mat. Sci. Eng. A. 378, 24 (2004)

16. R. Casati, F. Passaretti, A. Tuissi, Procedia Engineering 10, 3423 (2011)

17. S. Belyaev, N. Resnina, A. Sibirev, J. of Alloys and Compounds 542, 37 (2012)

18. S. Belyaev, N. Resnina, Int. J. of Materials Research 104, 11 (2013)

19. S. Belyaev, N. Resnina, A. Sibirev, J. of Materials Engineering and Performance 23, 2339 (2014)

20. A. Razov, A. Motorin, G. Nakhatova, J. of Alloys and Compounds 577 (Suppl.1), S164 (2013) 